\title{
Role of Catalysts in the Surface Synthesis of Single-Walled Carbon Nanotubes
}

\author{
Weiwei Zhou, Lei Ding, and Jie Liu $(\bowtie)$ \\ Department of Chemistry, Duke University, Durham, NC 27708, USA \\ Received: 18 April 2009 / Revised: 1 June 2009 / Accepted: 1 June 2009 \\ CTsinghua University Press and Springer-Verlag 2009. This article is published with open access at Springerlink.com
}

\begin{abstract}
We demonstrate the role of catalysts in the surface growth of single-walled carbon nanotubes (SWNTs) by reviewing recent progress in the surface synthesis of SWNTs. Three effects of catalysts on surface synthesis are studied: type of catalyst, the relationship between the size of catalyst particles and carbon feeding rates, and interactions between catalysts and substrates. Understanding of the role of catalysts will contribute to our ability to control the synthesis of SWNTs on various substrates and facilitate the fabrication of nanotube-based devices.
\end{abstract}

\section{KEYWORDS}

single-walled carbon nanotubes (CVD), surface growth, catalysts, chemical vapor deposition (CVD)

\section{Introduction}

Single-walled carbon nanotubes (SWNTs) are a kind of one-dimensional nanomaterial that promise to be one of the outstanding candidates for the stateof-the-art silicon industry of the future [1-3]. The controlled synthesis of SWNTs on surfaces has been thought of as the first and crucial step in the bottomup approach to construct highly integrated carbon nanotube (CNT), based circuits on chips $[4,5]$. However, compared with the rapid development of the bulk synthesis of SWNTs in the 1990s, progress in the surface growth of SWNTs was very slow until the first patterned growth of SWNTs on silicon wafers by chemical vapor deposition (CVD) in 1998 [6]. The reason is that the study of surface science was just at a beginning stage in the last century, and experimental and theoretical results were insufficient for a deep understanding of the surface growth of
SWNTs. In particular, the roles of catalysts in the surface growth are more complicated than in the bulk synthesis. The key factors which can effect the surface growth of SWNTs are not only the catalytic abilities of catalysts themselves, but also the interactions between catalysts and substrates and the relationship between catalysts and carbon feeding rates.

Recent investigations into the chemistry and physics involved in the interactions between catalysts, substrates, and carbon feeding gases, has led to many advances in the control of diameters [7 -15] and alignments [16-21] of SWNTs, and even in the selective growth of a high percentage of semiconducting $[22,23]$ SWNTs. Herein, we will discuss and summarize the effects of catalysts on the surface growth of SWNTs by the CVD method through presenting some outstanding work in the area of surface synthesis.

Address correspondence to j.liu@duke.edu 


\section{Effects of the type of catalysts}

Over the past ten years, much research has involved the seeking of new catalysts for improving the controllability and efficiency of SWNT growth. So far, besides the common iron-group metals $(\mathrm{Fe}, \mathrm{Co}, \mathrm{Ni})$, various metals such as $\mathrm{Au}[24,25], \mathrm{Cu}[22,26$, 27], Pd [28], Ag [29], Pt [29], Pd [29], Mn [29], Mo [29], Cr [29], Sn [29], Mg [29], and $\mathrm{Al}$ [29], have also been explored as catalysts for the growth of SWNTs on silicon or quartz substrates (Figs. 1 and 2). Especially copper, which was once considered the metal with the poorest catalytic efficiency for CNT growth, has been experimentally proven to have high activity in catalyzing the growth of dense aligned SWNT arrays on silicon [27] or quartz wafers [22, 26, 29].

Moreover, semiconductor and oxide nanoparticles, such as $\mathrm{Si}$ [30], $\mathrm{Ge}$ [30], $\mathrm{SiC}[30], \mathrm{SiO}_{2}[31,32], \mathrm{TiO}_{2}$ [32], $\mathrm{Al}_{2} \mathrm{O}_{3}$ [32], $\mathrm{La}_{2} \mathrm{O}_{3}$ [32], and $\mathrm{Er}_{2} \mathrm{O}_{3}$ [32], have also been successful in catalyzing the surface growth of SWNTs, which challenges the traditional opinion that metals are necessary for catalyzing the growth of SWNTs according to the vaporliquid-solid (VLS) mechanism [33]. The variety of catalysts used in surface growth indicates that the type of catalyst is not critical for catalyzing the growth of SWNTs. According to our understanding of the surface growth of SWNTs, it is much more important to optimize other growth conditions by changing experimental parameters such as growth temperatures and carbon feeding rates.

On the other hand, it should be noticed that there is some evidence of a narrow $(n, m)$ distribution of SWNTs synthesized by Co-Mo catalysts in the bulk synthesis [34], indicating that it is possible to precisely control the species of SWNT formed by using a certain type of catalyst. However, in the area of surface synthesis, few similar results have been reported because of the difficulty in identifying all indices $(n, m)$ of SWNTs on a surface using currently available techniques.

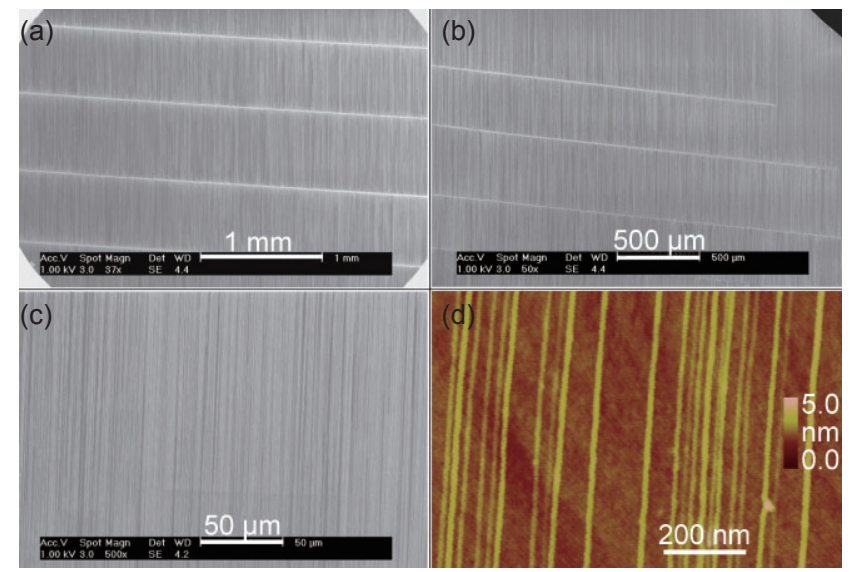

Figure 2 SEM and AFM images of high density and perfectly aligned arrays of long SWNTs along the [100] direction on an ST-cut quartz substrate using a patterned copper catalyst. Reproduced from Ref. [26]

\section{Importance of monodisperse catalyst nanoparticles in the surface growth of SWNTs}

The solubility of carbon in catalyst particles and the precipitation rates of carbon from catalyst particles both show great dependence on the size of catalyst particles, because quantum size effects greatly influence the properties of the catalyst particles when the size of particles is below ten nanometers [35]. Our earlier work has demonstrated that under 
a given CVD condition there is an optimal particle diameter to nucleate SWNTs with a fixed feeding rate of carbon. Smaller nanoparticles are easily poisoned due to "overfeeding", and larger nanoparticles are inactive due to "underfeeding" [36]. We also found that even for the same catalysts, the optimal feeding rates of carbon in the nucleation stage and the growth stage of SWNTs are different [37]. A narrow diameter distribution of SWNTs can be realized by merely controlling the carbon feeding rates, even when the catalyst particles have a wide distribution of diameters [36]. However, in order to obtain highly efficient growth of SWNTs with uniform diameters on surfaces, both exact control of the size of catalyst nanoparticles and choice of a proper feeding rate of carbon are necessary. There are a considerable number of papers presenting methods to control the size of catalyst nanoparticles, including direct synthesis of monodisperse nanoparticles by thermal decomposition of metal carbonyl complexes [7], by using metal-containing proteins $[9,10]$, polymers, and identical molecular nanoclusters as catalyst precursors [11, 13-15], and by using block copolymer micelles [38] or dendrimers [8] as synthetic templates for catalyst nanoparticles. Furthermore, it has been shown that the presence of polymers in the catalyst precursors not only contributes to the synthesis of monodisperse catalyst nanoparticles, but also can effectively prevent the aggregation of catalyst particles on the surface during the process of solvent evaporation. Well-dispersed catalyst particles on the substrates are crucial for realizing the highly efficient synthesis of SWNTs on substrates. For example, selfassembled block copolymer micelles were found to be good templates for tuning the spacing between catalyst nanoparticles on silicon wafers (Fig. 3, where AFM is atomic force microscopy; SEM is scanning electron microscopy) [38]. Another function of some photosensitive polymers is to fabricate catalyst patterns on the substrates and thus afford ordered structures of SWNTs on chips (Fig. 4) [39].

\section{Interactions between catalysts and substrates}

The interactions between catalysts and substrates can be generally described as van der Waals forces

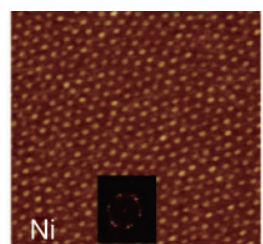

$2.3 \mathrm{~nm}$

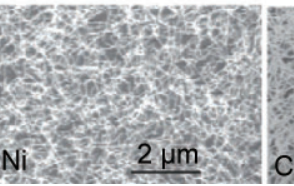

$\mathrm{Ni} \quad 2 \mu \mathrm{m}$.

Figure 3 AFM height images of metal nanoparticles (a) and corresponding SEM micrographs (b) of SWNT growth results. Reproduced from Ref. [38]

(a)

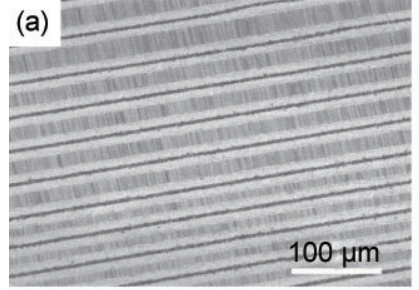

(c)

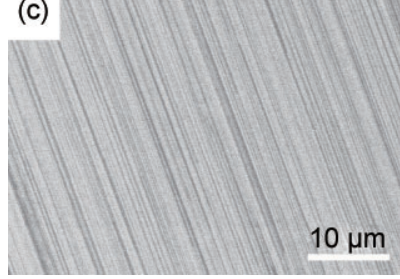

Figure 4 SEM images of large scale perfectly aligned arrays of SWNTs grown along the $x$ axis of ST-cut quartz wafer by using $\mathrm{FeCl}_{3} /$ Shipley 1827 photoresist as catalytic precursor and a simple photolithography technique to pattern the uniform catalyst lines. Reproduced from Ref. [39]

or/ and chemical reactions. A deep understanding of these interactions can guide us in predicting experimental results and explaining various growth phenomena. In the nucleation stage of CVD growth, the interactions between catalysts and substrates play a dominant role. For example, in the "fastheating" processes used to synthesize horizontal SWNT arrays on silicon wafers, the key step is to lift up the catalyst nanoparticles by overcoming their interactions with the substrate surface and let them float with a tube tailor (Fig. 5) [40]. Otherwise, the orientations of SWNTs cannot be guided by the gas flow due to the strong interactions between catalysts

\section{䈂 Springer}


and substrates resulting in catalysts staying on the surface. Therefore, weakening the interactions between catalysts and substrates can improve the growth efficiency of long SWNTs (Fig. 5) [27]. On the other hand, some transition metals such as Fe and Co can easily react with silicon and form silicides by diffusing through the $\mathrm{SiO}_{2}$ layer, or react with $\mathrm{SiO}_{2}$ and form silicates or covalent bonds with $\mathrm{SiO}_{2}$. These compounds have already been proven to be inactive for catalyzing the growth of SWNTs [41, 42]. In order to prevent catalysts from reacting with the silica surface and to decrease the interaction between catalysts and silica layers, a thin intermediate layer of $\mathrm{Al}_{2} \mathrm{O}_{3}$ has been successfully used to enhance the growth efficiency of SWNTs [43], especially for the synthesis of vertical SWNT forests on substrates (Fig. 6) $[44,45]$.
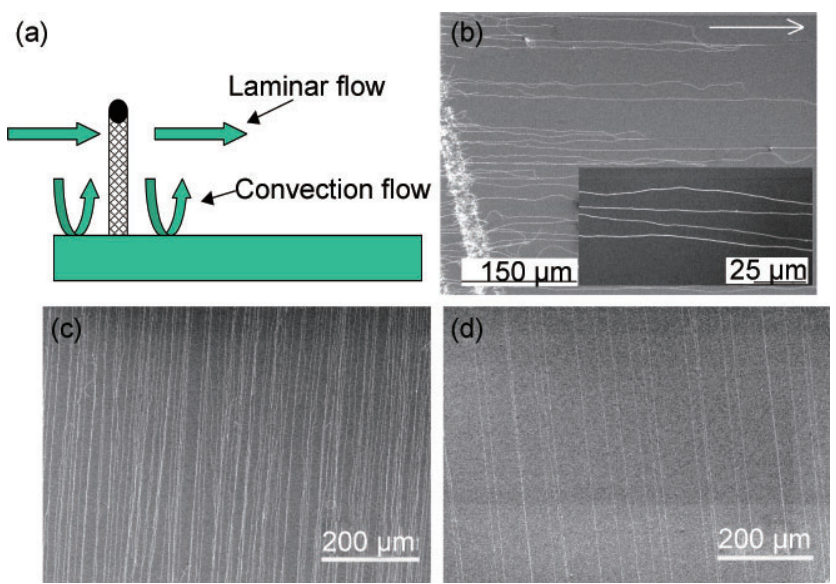

Figure 5 (a) Schematic illustration of the growth mechanism in the fast-heating process; (b) SEM image of horizontal long SWNTs grown on silicon wafers by using Fe as catalyst. (a) and (b) are reproduced from Ref. [40]. (c) and (d) SEM images of aligned array of SWNTS grown on a silicon wafer by using $\mathrm{Cu}$ as catalyst. Cu nanoparticles have high catalytic efficiency for the growth of horizontally aligned arrays of SWNTs on silicon wafers because of their weaker interactions with the substrate. Reproduced from Ref. [27]
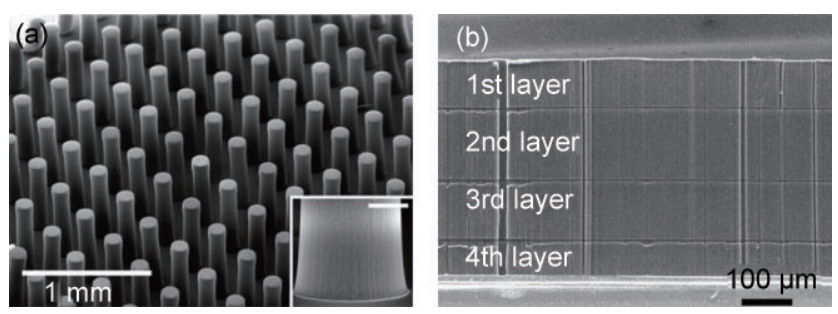

Figure 6 SEM images of vertically aligned SWNTs grown on silicon wafers by using a thin $\mathrm{Al}_{2} \mathrm{O}_{3}$ intermediate layer between the catalyst and $\mathrm{SiO}_{2}$ layers. Reproduced separately from Ref. [44] and Ref. [45]

\section{Conclusions}

Our review of the many publications in the area of surface synthesis of SWNTs indicates that catalysts play a central role in the CVD growth of SWNTs. A good catalyst should be monodisperse on the surface of a substrate, be matched with an appropriate feeding rate of carbon, and have appropriate interactions with substrates. So far, the published results concerning catalysts have mainly focused on the synthesis of monodisperse nanoparticles and theoretical explanations of the reaction between catalysts and carbon feeding gases and there have been very few detailed experimental studies of the reaction pathways. Moreover, the interactions between catalysts and the surfaces of substrates need to be further investigated and characterized. Our research efforts in the future will gradually be moving from finding optimal CVD conditions to discovering the detailed mechanism of catalysis, facilitating control over the growth of SWNTs and fabrication of a real "carbon nanotube world" on chips.

\section{References}

[1] Saito, R.; Dresselhaus, M. S.; Dresselhaus, G. Physical Properties of Carbon Nanotubes; World Scientific Publishing: Singapore, 1998.

[2] Anantram, M. P.; Leonard, F. Physics of carbon nanotube electronic devices. Rep. Prog. Phys. 2006, 69, 507-561.

[3] Javey, A.; Kim, H.; Brink, M.; Wang, Q.; Ural, A.; Guo, J.; McIntyre, P.; McEuen, P.; Lundstrom, M.; Dai, H. J. Highkappa dielectrics for advanced carbon-nanotube transistors and logic gates. Nat. Mater. 2002, 1, 241-246.

[4] Kang, S. J.; Kocabas, C.; Ozel, T.; Shim, M.; Pimparkar, N.; Alam, M. A.; Rotkin, S. V.; Rogers, J. A. Highperformance electronics using dense, perfectly aligned arrays of single-walled carbon nanotubes. Nat. Nanotechnol. 2007, 2, 230-236.

[5] Ishikawa, F. N.; Chang, H. K.; Ryu, K.; Chen, P. C.; Badmaev, A.; De Arco, L. G.; Shen, G. Z.; Zhou, C. W. Transparent electronics based on transfer printed aligned carbon nanotubes on rigid and flexible substrates. ACS Nano 2009, 3, 73-79.

[6] Kong, J.; Soh, H. T.; Cassell, A. M.; Quate, C. F.; Dai, H. 
J. Synthesis of individual single-walled carbon nanotubes on patterned silicon wafers. Nature 1998, 395, 878881.

[7] Li, Y.; Liu, J.; Wang, Y. Q.; Wang, Z. L. Preparation of monodispersed Fe-Mo nanoparticles as the catalyst for CVD synthesis of carbon nanotubes. Chem. Mater. 2001, 13, 1008-1014.

[8] Choi, H. C.; Kim, W.; Wang, D. W.; Dai, H. J. Delivery of catalytic metal species onto surfaces with dendrimer carriers for the synthesis of carbon nanotubes with narrow diameter distribution. J. Phys. Chem. B 2002, 106, 12361-12365.

[9] Jeong, G. H.; Yamazaki, A.; Suzuki, S.; Yoshimura, H.; Kobayashi, Y.; Homma, Y. Cobalt-filled apoferritin for suspended single-walled carbon nanotube growth with narrow diameter distribution J. Am. Chem. Soc. 2005, 127, 8238-8239.

[10] Li, Y. M.; Kim, W.; Zhang, Y. G.; Rolandi, M.; Wang, D. W.; Dai, H. J. Growth of single-walled carbon nanotubes from discrete catalytic nanoparticles of various sizes. J. Phys. Chem. B 2001, 105, 11424-11431.

[11] An, L.; Owens, J. M.; McNeil, L. E.; Liu, J. Synthesis of nearly uniform single-walled carbon nanotubes using identical inorganic metal-oxide-based molecular nanoclusters as catalysts. Abstr. Pap. Am. Chem. Soc. 2004, $227,150$.

[12] Fu, Q.; Huang, S. M.; Liu, J. Chemical vapor depositions of single-walled carbon nanotubes catalyzed by uniform $\mathrm{Fe}_{2} \mathrm{O}_{3}$ nanoclusters synthesized using diblock copolymer micelles. J. Phys. Chem. B 2004, 108, 6124-6129.

[13] Lu, J. Q.; Rider, D. A.; Onyegam, E.; Wang, H.; Winnik, M. A.; Manners, I.; Cheng, Q.; Fu, Q.; Liu, J. Carbon nanotubes with small and tunable diameters from poly(ferrocenylsilane)-block-polysiloxane diblock copolymers. Langmuir 2006, 22, 5174-5179.

[14] Lu, J. Q.; Moll, N.; Fu, Q.; Liu, J. Iron nanoparticles derived from iron-complexed polymethylglutarimide to produce high-quality lithographically defined single-walled carbon nanotubes. Chem. Mater. 2005, 17, 2237-2240.

[15] Lu, J. Q.; Kopley, T. E.; Moll, N.; Roitman, D.; Chamberlin, D.; Fu, Q.; Liu, J.; Russell, T. P.; Rider, D. A.; Manners, I.; Winnik, M. A. High-quality single-walled carbon nanotubes with small diameter, controlled density, and ordered locations using a polyferrocenylsilane block copolymer catalyst precursor. Chem. Mater. 2005, 17, 2227-2231.

[16] Zhang, Y. G.; Chang, A. L.; Cao, J.; Wang, Q.; Kim, W.;
Li, Y. M.; Morris, N.; Yenilmez, E.; Kong, J.; Dai, H. J. Electric-field-directed growth of aligned single-walled carbon nanotubes. Appl. Phys. Lett. 2001, 79, 31553157.

[17] Ismach, A.; Segev, L.; Wachtel, E.; Joselevich, E. Atomicstep-templated formation of single wall carbon nanotube patterns. Angew. Chem. Int. Ed. 2004, 43, 61406143.

[18] Liu, J. Abstr. Pap. Am. Chem. Soc. 2004, 227, U273.

[19] Kocabas, C.; Hur, S. H.; Gaur, A.; Meitl, M. A.; Shim, M.; Rogers, J. A. Guided growth of large-scale, horizontally aligned arrays of single-walled carbon nanotubes and their use in thin-film transistors. Small 2005, 1, 11101116.

[20] Han, S.; Liu, X. L.; Zhou, C. W. Template-free directional growth of single-walled carbon nanotubes on a- and r-plane sapphire. J. Am. Chem. Soc. 2005, 127, 52945295.

[21] Ago, H.; Nakamura, K.; Ikeda, K.; Uehara, N.; Ishigami, N.; Tsuji, M. Aligned growth of isolated single-walled carbon nanotubes programmed by atomic arrangement of substrate surface. Chem. Phys. Lett. 2005, 408, 433438.

[22] Ding, L.; Tselev, A.; Wang, J. Y.; Yuan, D. N.; Chu, H. B.; McNicholas, T. P.; Li, Y.; Liu, J. Selective growth of wellaligned semiconducting single-walled carbon nanotubes. Nano Lett. 2009, 9, 800-805.

[23] Li, Y. M.; Mann, D.; Rolandi, M.; Kim, W.; Ural, A.; Hung, S.; Javey, A.; Cao, J.; Wang, D. W.; Yenilmez, E.; Wang, Q.; Gibbons, J. F.; Nishi, Y.; Dai, H. J. Preferential growth of semiconducting single-walled carbon nanotubes by a plasma enhanced CVD method. Nano Lett. 2004, 4, 317 $-321$.

[24] Bhaviripudi, S.; Mile, E.; Steiner, S. A.; Zare, A. T.; Dresselhaus, M. S.; Belcher, A. M.; Kong, J. CVD synthesis of single-walled carbon nanotubes from gold nanoparticle catalysts. J. Am. Chem. Soc. 2007, 129, 1516-1517.

[25] Takagi, D.; Kobayashi, Y.; Hlbirio, H.; Suzuki, S.; Homma, $\mathrm{Y}$. Mechanism of gold-catalyzed carbon material growth. Nano Lett. 2008, 8, 832-835.

[26] Ding, L.; Yuan, D. N.; Liu, J. Growth of high-density parallel arrays of long single-walled carbon nanotubes on quartz substrates. J. Am. Chem. Soc. 2008, 130, 5428-5429.

[27] Zhou, W. W.; Han, Z. Y.; Wang, J. Y.; Zhang, Y.; Jin, Z.; 
Sun, X.; Zhang, Y. W.; Yan, C. H.; Li, Y. Copper catalyzing growth of single-walled carbon nanotubes on substrates. Nano Lett. 2006, 6, 2987-2990.

[28] Feng, Y. Y.; Zhang, H. B.; Hou, Y.; McNicholas, T. P.; Yuan, D. N.; Yang, S. W.; Ding, L.; Feng, W.; Liu, J. Room temperature purification of few-walled carbon nanotubes with high yield. ACS Nano 2008, 2, 1634-1638.

[29] Yuan, D. N.; Ding, L.; Chu, H. B.; Feng, Y. Y.; McNicholas, T. P.; Liu, J. Horizontally aligned single-walled carbon nanotube on quartz from a large variety of metal catalysts. Nano Lett. 2008, 8, 2576-2579.

[30] Takagi, D.; Hibino, H.; Suzuki, S.; Kobayashi, Y.; Homma, $Y$. Carbon nanotube growth from semiconductor nanoparticles. Nano Lett. 2007, 7, 2272-2275.

[31] Liu, B.; C., R. W.; Gao, L. B.; Li, S. S.; Pei, S. F.; Liu, C.; Jiang, C. B.; Cheng, H. -M. metal-catalyst-free growth of single-walled carbon nanotubes. J. Am. Chem. Soc. 2009, 131, 2082-2083.

[32] Huang, S. M.; Cai, Q.; Chen, J. Y.; Y, Q.; Zhang, L. J. Metal-catalyst-free growth of single-walled carbon nanotubes on substrates. J. Am. Chem. Soc. 2009, 131, 2094-2095.

[33] Saito, Y. Nanoparticles and filled nanocapsules. Carbon 1995, 33, 979-988.

[34] Lolli, G.; Zhang, L. A.; Balzano, L.; Sakulchaicharoen, N.; Tan, Y. Q.; Resasco, D. E. Tailoring $(n, m)$ structure of single-walled carbon nanotubes by modifying reaction conditions and the nature of the support of CoMo catalysts. J. Phys. Chem. B 2006, 110, 2108-2115.

[35] Buffat, P.; Borel, J. P. Size effect on melting temperature of gold particles. Phys. Rev. A 1976, 13, 2287.

[36] Lu, C. G.; Liu, J. Controlling the diameter of carbon nanotubes in chemical vapor deposition method by carbon feeding. J. Phys. Chem. B 2006, 110, 2025420257.

[37] Qi, H.; Yuan, D. N.; Liu, J. Two-stage growth of singlewalled carbon nanotubes. J. Phys. Chem. C 2007, 111, 6158-6160.
[38] Lu, J.; Yi, S. S.; Kopley, T.; Qian, C.; Liu, J.; Gulari, E. Fabrication of ordered catalytically active nanoparticles derived from block copolymer micelle templates for controllable synthesis of single-walled carbon nanotubes. J. Phys. Chem. B 2006, 110, 6655-6660.

[39] Zhou, W. W.; Rutherglen, C.; Burke, P. J. Wafer scale synthesis of dense aligned arrays of single-walled carbon nanotubes. Nano Res. 2008, 1, 158-165.

[40] Huang, S. M.; Woodson, M.; Smalley, R.; Liu, J. Growth mechanism of oriented long single walled carbon nanotubes using "fast-heating" chemical vapor deposition process. Nano Lett. 2004, 4, 1025-1028.

[41] Maeda, F.; Laffosse, E.; Watanabe, Y.; Suzuki, S.; Homma, Y.; Suzuki, M.; Kitada, T.; Ogiwara, T.; Tanaka, A.; Kimura, M.; Mihai, V. A.; Yoshikawa, H.; Fukushima, S. Surface and interface reactions of catalysts for carbon nanotube growth on Si substrates studied by soft X-ray photoelectron spectroscopy. Phys. E 2004, 24, 19-25.

[42] Murakami, T.; Mitikami, K.; Ishigaki, S.; Matsumoto, K.; Nishio, K.; Isshiki, T.; Harima, H.; Kisoda, K. Catalytic mechanism of a Fe-Co bimetallic system for efficient growth of single-walled carbon nanotubes on $\mathrm{Si} / \mathrm{SiO}_{2}$ substrates. J. Appl. Phys. 2006, 100, 094303.

[43] Mizuno, K.; Hata, K.; Saito, T.; Ohshima, S.; Yumura, M.; lijima, S. Selective matching of catalyst element and carbon source in single-walled carbon nanotube synthesis on silicon substrates. J. Phys. Chem. B 2005, 109, 26322637.

[44] Hata, K.; Futaba, D. N.; Mizuno, K.; Namai, T.; Yumura, M.; lijima, S. Water-assisted highly efficient synthesis of impurity-free single-waited carbon nanotubes. Science 2004, 306, 1362-1364

[45] Iwasaki, T.; Zhong, G. F.; Aikawa, T.; Yoshida, T.; Kawarada, H. Direct evidence for root growth of vertically aligned single-walled carbon nanotubes by microwave plasma chemical vapor deposition. J. Phys. Chem. B 2005, 109, 19556-19959. 